\title{
Limb reduction defects in the northern region of England 1985-92
}

\author{
M J Wright, J N Newell, M E Charlton, E N Hey, LJ Donaldson, J Burn
}

\begin{abstract}
Study objective - To test the hypothesis that children born to mothers living near the sea are at increased risk of limb reduction defects.

Design - Descriptive data analysis.

Setting - The northern health region of England.

Patients - All children born between 1 January 1985 and 31 December 1992 in the northern region of England with isolated limb reduction defects.

Main results - The birth prevalence of isolated limb reduction defects was not affected by the distance the mother lived from the sea. There was some evidence of space-time clustering, but there was no evidence of statistically significant variation in the occurrence of the condition with sex, time of birth (monthly or yearly), or county of birth.

Conclusions - There is no evidence that children born to mothers living near the sea are at increased risk of limb reduction defects.
\end{abstract}

( $($ Epidemiol Community Health 1995;49:305-308)

Early in 1994 several possible "clusters" of limb reduction defects were identified in the British Isles including one in north east England. ${ }^{1}$ Media coverage of these gave rise to wide public concern, particularly that an abnormal occurrence of this condition might be associated with proximity to the sea.

We have identified children with limb reduction defects born between 1985 and 1992 to mothers resident in the northern region at the time of delivery. Previous studies have addressed the hypothesis that proximity to the sea was an aetiological factor in limb reduction defects and have shown no association. ${ }^{2-4}$ We have looked at this in much more detail using precise mapping of cases. We have also investigated the possibility that there was clustering in time, space, or space-time.

Department of Epidemiology and Public Health L J Donaldson

University of Newcastle upon Tyne, Newcastle upon Tyne

Correspondence to: Dr M J Wright, Department of Human Genetics, 19 Claremont Place, Newcastle upon Tyne NE2 4AA.

Accepted for publication February 1995 million. The region has two coastlines, one in Cumbria in the west and one in the east stretching from Berwick through Tyneside and Wearside to Cleveland.

The population at risk comprised all births between 1 January 1985 and 31 December 1992 to a mother resident in the study area. The further inclusion criterion for cases was documented definite evidence of an isolated limb reduction defect. The categories used in the British Columbia study by Froster and Baird $^{5}$ were used to define limb reduction defects. We chose to exclude isolated syndactyly but included syndactyly where it was associated with some other limb reduction event. Children with a limb reduction defect were excluded if they had evidence of an associated abnormality affecting another organ system, such as a congenital cardiac malformation, or whose pattern of malformation allowed a recognised syndromic diagnosis, such as Cornelia de Lange syndrome, ${ }^{6}$ to be made. Where the original notification was too vague to allow a definite diagnosis of a limb reduction defect, and no other information could be obtained, the child was excluded from the study.

The two primary sources for the identification of cases were the fetal abnormality survey (FAS), a cumulative population based register maintained in the northern region for the past 10 years, and the national register of congenital malformations maintained by The Office of Population Censuses and Surveys (OPCS). Five further sources were used to identify potential cases: parents who contacted FAS after the initial publicity, the parent support group REACH, disablement services centres, clinicians working in the region and a postal survey of the headteachers of 1495 schools in the region with pupils in the appropriate age range.

FAS and OPCS databases were searched to extract all records coded to ICD $-9^{7}$ code 755- ("other congenital anomalies of limbs") identifying any congenital limb malformation not associated with another abnormality. These were then analysed by one of the authors (MJW) to select the children with a limb reduction defect as defined by Froster and Baird. The date of birth, sex, postcode of mother's residence at the time of delivery, full ICD-9 code, and a description of the defect(s) as recorded in the relevant database was thus obtained. Parents contacting FAS were asked to give similar details and offered a consultation with one of the authors (MJW). Clinicians, limb fitting centres, and schools were asked for the child's date of birth, sex, postcode, and a description of the defects. The data from the 
various sources were compared to avoid double counting and to permit cross validation of children appearing in more than one source.

A birth register of all live births in the study area between 1985 and 1992 inclusive including their postcode locations was obtained from anonymised returns previously made available to the Northern Regional Health Authority by OPCS.

\section{GEOGRAPHICAL METHODS}

Using the 1991 census Directory of Enumeration Districts and Postcodes (CDEDP), ${ }^{8}$ cases were allocated to a county and to an enumeration district (ED) and hence to a grid reference. Using the geographical information system package ARC/INFO, ${ }^{9}$ and a digitised coastline of Great Britain, ${ }^{10}$ the shortest distance from each case to the sea was calculated. To provide corresponding child at risk data, a similar procedure was followed for every birth on the birth register. For the purposes of this study, the sea did not include the estuarine waters of the rivers Tyne, Wear, or Tees.

When matching the postcodes of cases to those available in the CDEDP, ${ }^{8}$ no match could be found for five. The full addresses of these were checked and the grid references allocated manually from 1:2500 scale maps. When matching cases to the birth register, six cases could not be matched exactly to a birth with the same date of birth in the same postcode. For three of these there was a birth with the same date of birth in a neighbouring postcode. One case was found to have been incorrectly postcoded and correction of this produced a match.

Of the 322483 live births on the birth register, $316603(98.2 \%)$ fully matched a postcode in the CDEDP, ${ }^{8} 5447(1 \cdot 7 \%)$ could be matched to all but the last character of the postcode, giving an error nearly always less than $200 \mathrm{~m}$, and $196(0 \cdot 1 \%)$ could only be matched to the postcode sector (that is, all but the last two characters of the postcode). A further $382(0 \cdot 1 \%)$ could not be matched from geographical analyses, and were excluded, leaving a total of 322101 births. There was no clear pattern among the excluded or less than perfectly matched births, either by approximate location or by year of birth.

\section{STATISTICAL METHODS}

Association between proximity to the sea and a limb reduction defect was investigated using rates of LRD in five bands: less than or equal to $2.5 \mathrm{~km}$ from the sea, greater than $2.5 \mathrm{~km}$ but less than or equal to $5.0 \mathrm{~km}$, greater than $5.0 \mathrm{~km}$ but less than or equal to $7.5 \mathrm{~km}$, greater than $7.5 \mathrm{~km}$ but less than or equal to $10 \mathrm{~km}$, and greater than $10 \mathrm{~km}$ from the sea. These distances were chosen before inspecting the data. Interactions between possible risk factors available: county of residence, proximity to the sea and sex were explored using logistic regression.

Space-time clustering was investigated using Knox's statistic, ${ }^{11}$ in which numbers of cases close both in space and in time are calculated. The significance of this observed statistic was computed using 10000 Monte Carlo simulations: in each simulation a fixed number of cases was randomly chosen from the births. No modifications to allow for possible population movement were necessary, since the population at risk was fully defined. We used three thresholds to define closeness in time $(30,90$, and 180 days), and two thresholds to define closeness in space ( 5 and $10 \mathrm{~km}$ ), again selected before inspecting the data.

\section{Results}

A total of 135 children with an isolated limb reduction defect were found. Of these, 128 were identified using OPCS and FAS, five previously unrecorded cases were notified to FAS by parents and two were notified by headmasters. The corresponding total number of live births was 322483 , giving a crude birth prevalence of limb reduction defects of 419 per million births over the eight year period. There was no statistically significant difference between the number of affected male and female children (70/165 469 males, 65/157014 females, $\chi^{2}=0.02$ on $1 \mathrm{df}, \mathrm{p}=0.9$ ). There was no evidence of any yearly or monthly variation in birth prevalence $\left(\chi^{2}=5.3\right.$ on $7 \mathrm{df}, \mathrm{p}=0.63$ and $\chi^{2}=3.2$ on $11 \mathrm{df}, \mathrm{p}=0.98$ respectively). There was no significant difference in the rates between the five counties $\left(\chi^{2}=5.0\right.$ on $4 \mathrm{df}, \mathrm{p}=$ $0 \cdot 29)$.

Among the 135 cases, 101 had upper limb reduction defect, of whom 92 had an upper defect only. When the distribution of defects among affected limbs was explored, it was found that significantly more were upper than lower (113 versus $54, \chi^{2}=20.8$ on $1 \mathrm{df}, \mathrm{p}=$ 0.001 ( 5 unclassified)). There was no significant difference between side of limb reduction defect, either when considered for children (46 children had a right sided limb

Table 1 Distribution of limb reduction defects by proximity of place of residence to the sea at the time of birth in the northern region

\begin{tabular}{llllll}
\hline Distance from sea $(\mathrm{km})$ & $d>10 \cdot 0$ & $7 \cdot 5<d \leq 10 \cdot 0$ & $5 \cdot 0<d \leq 7 \cdot 5$ & $2 \cdot 5<d \leq 5 \cdot 0$ & $0 \leq d \leq 2 \cdot 5$ \\
\hline Live births & 147755 & 37626 & 32032 & 35124 & 69564 \\
All cases & 59 & 12 & 13 & 23 & 28 \\
OR & 1 & $0 \cdot 8$ & $1 \cdot 02$ & $1 \cdot 64$ & $1 \cdot 01$ \\
(95\% CI) & 43 & $(0 \cdot 4,1 \cdot 5)$ & $(0 \cdot 5,1 \cdot 9)$ & $(1 \cdot 0,2 \cdot 7)$ & $(0 \cdot 6,1 \cdot 6)$ \\
Any upper limb defect & 1 & 9 & 10 & 19 & 0 \\
OR & - & $0 \cdot 82$ & $1 \cdot 07$ & $1 \cdot 86$ & 0.96 \\
(95\% CI) & $(0 \cdot 4,1 \cdot 8)$ & $(0 \cdot 5,2 \cdot 2)$ & $(1 \cdot 0,3 \cdot 3)$ & $(0 \cdot 6,1 \cdot 7)$ \\
\hline
\end{tabular}

All cases: test for overall difference $\chi^{2}=5.76$ on $4 \mathrm{df}, \mathrm{p}=0.22$ (test for $\leq 10.0 \mathrm{~km}$ versus $>10.0 \mathrm{~km}: \chi^{2}=0.26$ on $1 \mathrm{df}, \mathrm{p}=0.61$ ) Any upper limb defect: test for overall difference $\chi^{2}=6.85$ on $4 \mathrm{df}, \mathrm{p}=0.14$ (test for $\leq 10.0 \mathrm{~km}$ versus $>10.0 \mathrm{~km}: \chi^{2}=0.45$ on $1 \mathrm{df}$, $\mathrm{p}=0.51$.

$\mathrm{p}=0.51$ ) 
Table 2 Results from Knox's test for space-time clustering

\begin{tabular}{lll}
\hline Definition of a close-close pair & No of close-close pairs & $\begin{array}{l}\text { Probability of observing this many or } \\
\text { more close-close pair** }\end{array}$ \\
\hline$\leq 5 \mathrm{~km}$ and $\leq 30 \mathrm{~d}$ & 12 & 0.03 to 0.06 \\
$\leq 10 \mathrm{~km}$ and $\leq 30 \mathrm{~d}$ & 21 & 0.33 to 0.40 \\
$\leq 5 \mathrm{~km}$ and $\leq 90 \mathrm{~d}$ & 30 & 0.04 to 0.05 \\
$\leq 10 \mathrm{~km}$ and $\leq 90 \mathrm{~d}$ & 58 & 0.42 to 0.46 \\
$\leq 5 \mathrm{~km}$ and $\leq 180 \mathrm{~d}$ & 42 & 0.36 to 0.40 \\
$\leq 10 \mathrm{~km}$ and $\leq 180 \mathrm{~d}$ & 106 & 0.61 to 0.63 \\
\hline
\end{tabular}

* Calculated from 10000 Monte Carlo simulations, in each of which 135 randomly selected births were allocated case status and the number of close-close pairs calculated. Because of the discrete nature of the statistic, only a range of probabilities can be calculated.

reduction defect only versus 54 with left sided only, $\left(\chi^{2}=0.64\right.$ with $1 \mathrm{df}, \mathrm{p}=0.42$ (13 unclassified, 22 others with both right and left defects)) or for affected limbs (75 right sided affected limbs versus 84 left sided affected limbs $\left(\chi^{2}=0.51\right.$ with $1 \mathrm{df}, \mathrm{p}=0.48$ (13 unclassified)).

Table 1 shows the distribution of cases with a limb reduction defect in relation to closeness to the sea at the time of birth. There were no significant associations with raised birth prevalence either of all limb reduction defects $\left(\chi^{2}=5 \cdot 76\right.$ on $\left.4 \mathrm{df}, \mathrm{p}=0.22\right)$ or upper defects only $\left(\chi^{2}=6 \cdot 85\right.$ on $\left.4 \mathrm{df}, \mathrm{p}=0 \cdot 14\right)$. Although the greater than $2.5 \mathrm{~km}$ but less than or equal to $5 \mathrm{~km}$ band produces an OR of marginally significantly greater than 1 , in each case the tests for overall difference do not show a significant result. Likewise, no association was found for the categories upper limb reduction defect only, lower limb reduction defect only, right limb reduction defect only, left limb reduction defect only, limb reduction defect involving the hand, and limb reduction defect affecting the hand only. Logistic regression analysis showed no interaction between proximity to the sea, county of residence, and/or sex for any category.

The numbers of case pairs close both in space and time resulting from Knox's method, ${ }^{11}$ together with their corresponding probabilities, are given in table 2 . There was some evidence of space-time clustering at small spatial separation. Similar methods were used to look separately at the numbers of cases close in space (using the same distance separations), and close in time (using the same time separations). In no case was any $p$ value less than $0 \cdot 6$, implying there was clustering neither purely in space nor purely in time.

\section{Discussion}

We have found the birth prevalence of isolated limb reduction defects in the northern region to be 419 per million live births. This is significantly higher than that reported for England and Wales ${ }^{2}$ (344 per million $p<0.05$ ) and significantly lower than that reported from Italy ${ }^{4}$ ( 545 per million $p<0.01$ ) but not significantly different from that reported from Brazil (479 per million $\mathrm{p}>0 \cdot 1){ }^{3}$ The increased birth prevalence compared to the whole of England and Wales may be explained by the under-reporting acknowledged by the OPCS. ${ }^{2}$ The reduced birth prevalence compared to Italy may possibly be explained by different exclusion criteria. ${ }^{4}$

The hypothesis that children born to mothers living close to the sea might be at increased risk of limb reduction defects was inherently weak from the outset. The groups around Britain which formed the basis of the hypothesis were exposed to the English Channel, the North Sea, the Irish Sea, and the Atlantic. Any sea borne teratogen would need to be widely dispersed. A much more obvious explanation of proximity of affected children to the sea was the population distribution of the British Isles. In our own analysis, we found that $50 \%$ of babies born in the northern region of England live within $10 \mathrm{~km}$ of the coast. It is thus to be expected that any group of abnormalities would be seen more commonly on the coastal strip.

Previous studies have been limited by the need for an initial rapid response and hence by the quality of data available at the time. Analysis of populations from districts which have a coast or studies of children known to have been born in coastal hospitals are both open to bias. ${ }^{34} \mathrm{~A}$ genuine association of proximity of residence to the sea might have been obscured by the limitations of such studies.

The initial public concern which prompted our study was that there might be a significant excess of children with limb defects born close to the sea. We formally addressed this question in two ways. Firstly, we identified by postcode linkage the residence of every birth in relation to the coastline and analysed these data both using a simple $10 \mathrm{~km}$ division and by subdividing the families near the coast into $2.5 \mathrm{~km}$ bands. There was no overall evidence of excessive grouping in the $10 \mathrm{~km}$ coastal band and no evidence of a "dose gradient" within the $10 \mathrm{~km}$ strip.

Secondly, we looked for evidence of space clustering, time clustering and space-time clustering. This did not show any evidence of significant grouping in space or time independently. We performed space-time cluster analysis using Knox's method ${ }^{11}$ and the Monte Carlo simulation. This only gave weakly statistically significant findings in two categories with an excess of observed over expected cases born less than $5 \mathrm{~km}$ apart in the 30 and 90 day groups. These findings are worthy of further investigation but they may be artefactual. The fact that there was no significant spatial clustering strongly suggests that there is no unknown genetic cause. If there was, one might expect to identify occasional families with multiple affected siblings, which would produce a space cluster but no time cluster. Weakly significant space-time clustering could be compatible with a relatively low grade teratogen affecting small groups of the population on an episodic basis. 
The quality of ascertainment is the single most important factor in analyses of this type. Using the two officially available sources of data, $94.8 \%$ of the total cases identified were ascertained. This is not surprising as limb reduction defects are usually obvious at birth and therefore notification should be high. It is interesting, however, that seven cases only came to light from direct contact with the public and schools. These sources of information were particularly useful in establishing that there was not a large unidentified cohort of children in the community with a limb reduction defect which had not been detected by FAS or OPCS.

There is a risk that ascertainment of minor defects may be less than complete. It is not difficult to identify and recognise the clinical significance of a missing limb or even a missing hand but missing finger tips might be overlooked and considered to be of little clinical importance. From the epidemiological point of view, however, they may represent the effects of a similar teratogenic insult and their inclusion may lead to the identification of a causal mechanism which would be overlooked if only the more extreme cases were analysed.

Ideally, any analysis of the type presented here should be based on data evaluated by an experienced clinical observer. It is unrealistic to demand this on a prospective basis. The recent introduction by the national notification scheme of diagrams which allow the notifying health care unit to select the most appropriate description visually as well as using written descriptions, should improve notification of limb defects for the future. ${ }^{12}$ It must be remembered that reduction defects of the limbs are the easiest malformation to ascertain be- cause in their isolated form they are almost never associated with termination of pregnancy, they are recognisable at delivery and the prolonged survival of the children ensures their continuing contact with the medical services. The series of events which led to limb reduction defects becoming the focus of international attention has emphasised the continuing need for a reliable method of malformation ascertainment. We thank the following people without whom this project would
not have been possible: Jackie Driver and her team at OPCS for their hard work extracting SD56 forms. Valerie Lockie at for their hard work extracting SD56 forms. Valerie Lockie at with population data. Marjorie Renwick and her team at FAS. with population data. Marjorie Renwick and her team at FAS. Oonagh Claber and Gail Barker for extraordinary postal duties.
All the parents, doctors, and headteachers who have reported children to us.

MJW and JNN were supported by a grant from Northern and Yorkshire Regional Health Authority.

1 Ryan S. Inquiry ordered into mystery of handless babies near coasts. Sunday Times London, Jan 23, 1994.

2 Botting BJ. Limb reduction defects and coastal areas [letter] Lancet 1994;343:1033-34.

3 Castilla EE, da Graca Dutra M. Limb reduction defects and coastal areas [letter] Lancet 1994;343:1034.

4 Mastroiacovo P, Botto L, Fusco D, Rosano A, Scarano G. Limb reduction defects and coastal areas [letter] Lancet 1994;343:1034-35

5 Froster UG, Baird PA. Upper limb deficiencies and associated malformations: A population based study. $\operatorname{Am~} \mathcal{F}$ Med Genet 1992;44:767-81.

6 Ireland M, Burn J. Cornelia de Lange syndrome - photo essay. Clinical Dysmorphology 1993;2:151-60.

7 World Health Organization. International classification of diseases. 9th Revision 1978 Geneva: WHO, Switzerland.

8 Office of Population Censuses and Surveys. Directory of enumeration districts and postcodes. 1991 census user guide enumeration districts and postcodes. 1991 census
26. Titchfield, Hampshire, UK: OPCS 1994.

9 Environmental Systems Research Institute. ARC/INFO 6.1 documentation. Redlands, California: ESRI 1992.

10 Digitised Boundary Data Series (1981 Census) Study number 2357. Colchester: Economic and Social Research Council Data Archive, University of Essex.

11 Knox G. The detection of space time interactions. Appl Stat 1964;13:25-29.

12 Office of Population Censuses and Surveys. Congenital malformation notification scheme OPCS Newsletter No 5 , October 1990 